\title{
Production of copolyesters of 3-hydroxybutyrate and medium-chain-length 3-hydroxyalkanoates by E. coli containing an optimized PHA synthase gene
}

\author{
Xue Gao ${ }^{1+}$, Xiao-Xi Yuan ${ }^{1 \dagger}$, Zhen-Yu Shi ${ }^{2}$, Ying-Ying Guo ${ }^{1}$, Xiao-Wen Shen ${ }^{1}$, Jin-Chun Chen ${ }^{1}$, Qiong Wu ${ }^{1 *}$ \\ and Guo-Qiang Chen ${ }^{1,3^{*}}$
}

\begin{abstract}
Background: Microbial polyhydroxyalkanoates (PHA) are biopolyesters consisting of diverse monomers. PHA synthase PhaC2 $\mathrm{ps}_{\mathrm{s}}$ cloned from Pseudomonas stutzeri 1317 is able to polymerize short-chain-length (scl) 3-hydroxybutyrate $(3 \mathrm{HB})$ monomers and medium-chain-length $(\mathrm{mcl})$ 3-hydroxyalkanoates $(3 \mathrm{HA})$ with carbon chain lengths ranging from C6 to C12. However, the scl and mcl PHA production in Escherichia coli expressing PhaC2 $p_{s}$ is limited with very low PHA yield.

Results: To improve the production of PHA with a wide range of monomer compositions in $E$. coli, a series of

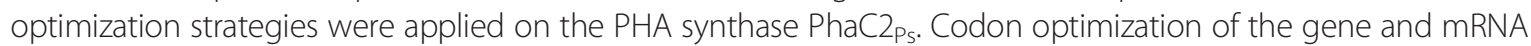
stabilization with a hairpin structure were conducted and the function of the optimized PHA synthase was tested in $E$. coli. The transcript was more stable after the hairpin structure was introduced, and western blot analysis showed that both codon optimization and hairpin introduction increased the protein expression level. Compared with the wild type PhaC2 $p_{s}$, the optimized PhaC2 $p_{s}$ increased poly-3-hydroxybutyrate (PHB) production by approximately 16 -fold to $30 \%$ of the cell dry weight. When grown on dodecanoate, the recombinant $E$. coli harboring the optimized gene phaC $2 p_{s} O$ with a hairpin structure in the $5^{\prime}$ untranslated region was able to synthesize 4-fold more PHA consisting of $3 \mathrm{HB}$ and medium-chain-length $3 \mathrm{HA}$ compared to the recombinant harboring the wild type phaC2 $2_{s}$.

Conclusions: The levels of both PHB and scl-mcl PHA in E. coli were significantly increased by series of optimization strategies applied on PHA synthase PhaC2ps. These results indicate that strategies including codon optimization and mRNA stabilization are useful for heterologous PHA synthase expression and therefore enhance PHA production.
\end{abstract}

Keywords: PHB, Polyhydroxyalkanoates, PHA synthase, Codon optimization, Hairpin, Escherichia coli

\section{Background}

Polyhydroxyalkanoates (PHA) are a family of biopolyesters accumulated by many bacteria, and have been studied to meet the various demands in chemical, material and special industries [1-6]. The structures and properties of PHA can be adjusted by controlling their monomer compositions

\footnotetext{
*Correspondence: wuqiong@mail.tsinghua.edu.cn; chengq@mail.tsinghua. edu.cn

${ }^{\dagger}$ Equal contributors

'MOE Key Lab of Bioinformatics, Department of Biological Science and Biotechnology, School of Life Science, Tsinghua-Peking Center for Life Sciences, Tsinghua University, Beijing 100084, China

${ }^{3}$ Center for Nano and Micro Mechanics, Tsinghua University, Beijing 100084, China Full list of author information is available at the end of the article
}

$[7,8]$. On the basis of the carbon chain lengths of monomers, PHA are classified as short-chain-length PHA (scl PHA) and medium-chain-length PHA (mcl PHA) consisting of three to five and six or more carbon atoms in their monomers, respectively [7,9]. The differences in PHA monomers and compositions can strongly affect the properties and qualities of the polyesters [10-12]. Generally, PHA copolymers consisting of scl and mcl monomers are considered to have more potentials for applications due to their suitable properties including tensile strength, Young's modulus, elongation at break and so on [13]. Particularly, the scl and mcl PHA copolymers consisting of high molar percentage of scl monomers (such as $3 \mathrm{HB}$ ) and low molar

\section{Biomed Central}


percentage of mcl monomers have better application properties including high melting temperature and toughness as well as rapid crystallization process [14]. Many bacteria such as Aeromonas hydrophila and Ralstonia eutropha were reported to be able to produce scl and mcl PHA with different compositions and yields $[15,16]$. However, there are still difficulties to control the PHA monomer compositions when industrial fermentation processes are conducted for production of PHA [8].

One of the key factors that determine PHA monomers composition is the substrate specificity of the PHA synthase (PhaC). The production of $\mathrm{scl}$ and $\mathrm{mcl}$ PHA requires synthases with relatively wide substrate specificities, such as PhaC from Aeromonas caviae $[17,18]$ and PhaC2 $2_{\mathrm{Ps}}$ from Pseudomonas stutzeri 1317 (named PhaC2 $2_{\mathrm{Ps}}$ ) [19]. These PHA synthases have been well characterized and expressed for production of $\mathrm{scl}$ and mcl copolymers $[17,19]$. For example, when expressed in a PHA synthase gene $p h b C_{\mathrm{Re}}$ negative mutant $R$. eutropha PHB-4, PhaC2 $2_{\mathrm{Ps}}$ could confer on the host strain the ability to synthesize PHA with monomer compositions adjustable by altering carbon sources [19]. Furthermore, to achieve a high mole faction of 3-hydroxybutyrate (3HB) monomer in scl-mcl PHA copolymers for better thermal and mechanical properties, specific point mutagenesis was successfully applied [20], leading to mutated PHA synthase PhaC2 $2_{\mathrm{Ps}} \mathrm{QKST}$ that increased PHA accumulation up to $42 \mathrm{wt} \%$ consisting of $93 \mathrm{~mol} \% 3 \mathrm{HB}$ in $R$. eutropha PHB-4. However, all of the PhaC2 $2_{\mathrm{Ps}}$ mutants have not yet been characterized in $E$. coli which is a well-developed cell factory for many fine products [21].

E. coli was successfully exploited for scl PHA [22] and scl-mcl PHA production [23,24]. Particularly, pathways were constructed to achieve scl-mcl PHA accumulation in E. coli using related or unrelated carbon sources [25-27]. However, the overall PHA yields were generally low probably due to inadequate supply of PHA precursors, and/or lower synthase activity during the polymerization process.

The stability of mRNA is one of the most significant factors that affect levels of protein synthesis, in this case, PHA synthase synthesis. It was reported that the secondary structures within 5' untranslated regions (UTRs) of prokaryotic mRNA could act as mRNA stabilizers, prevent them from fast degradation by RNases and therefore promote translation [28]. Various rationally designed synthetic 5' hairpin structures have been investigated and their half lives and effects in mRNA stability were measured $[28,29]$, and it is significant to add different mRNA secondary structures in the 5' UTR region for controlling the expression of recombinant genes. On the other hand, species-specific variations in codon usage are generally considered one of the major factors that affect heterologous protein expressions. If the concentrations of the E. coli tRNAs for the rare codons are insufficient to optimally translate mRNA [30], codon optimization could be effective to enhance protein expression [31,32].

To achieve high scl-mcl PHA production, the functions of the wild type phaC2 $2_{P s}$ and its recombinants in $E$. coli were evaluated in this study, and codon optimization and mRNA stabilization strategy were employed to enhance PHA synthase expression. The recombinant $E$. coli expressing the optimized $\mathrm{PhaC} 22_{\mathrm{Ps}}$ was proven to be able to produce scl-mcl PHA much more effectively than the wild type did.

\section{Results}

\section{Analysis and optimization of the mutated PHA synthase PhaC2 ps QKST}

In previous studies, the scl-mcl PHA production abilities of several mutants of $\mathrm{PhaC} 22_{\mathrm{Ps}}$ were studied [20]. A double mutant of $\mathrm{PhaC} 2_{\mathrm{Ps}}$ named PhaC2 $2_{\mathrm{Ps}} \mathrm{QKST}$ was shown to have higher scl-mcl PHA productivity and altered substrate specificity. When this mutated PHA synthase was expressed in $R$. eutropha PHB-4, the recombinant was reported to produce $42 \mathrm{wt} \% \mathrm{scl}-\mathrm{mcl}$ PHA [20]. However, the expression of this enzyme in $E$. coli was not high enough for producing large amount of PHA (Figure 1). Codon analysis of the original phaC $2_{P S} Q K S T$ gene revealed that almost $60 \%$ codons were not preferred in $E$. coli. For example, in a total of 23 codons for lysine, 21 codons are AAG with a frequency of $27 \%$ in the $E$. coli genome, while only 2 codons are AAA with a frequency of $73 \%$. Very rare codons such as AGG (Arg) and CUA (Leu) also exist. Thus, codon optimization of the phaC $2_{P S} Q K S T$ gene may improve productivity by increasing protein expression. Therefore, PhaC $2_{\mathrm{Ps}} \mathrm{QKST}$ was optimized by "one amino acid-one codon" strategy, resulting in new PHA synthase gene phaC2 ${ }_{P S} \mathrm{O}$ (Figure 2). Also, the GC content of the coding sequence was adjusted from $66.7 \%$ to $58.3 \%$.

To further enhance the expression level of the target protein, the hairpin structure pHP17 (Figure 2), which was reported to have the longest half life among a hairpin mRNA pool [29], was chosen to evaluate its effect on the expression of PhaC $2_{\mathrm{Ps}} \mathrm{QKST}$. To do this, $\mathrm{pHP} 17$ was inserted to the upstream of the gene phaC2 $2_{P_{S}} O$, resulting in phaC2 $2_{P S} \mathrm{OH}$ [GenBank: JX082171].

\section{Effect of the optimization strategies on mRNA degradation and protein expression of phaC2 $p_{s}$}

To assess the effect of codon optimization and hairpin stabilization, five pET28a-based plasmids were constructed expressing different phaC2 $2_{P s}$ genes, namely pETC2, pETC2QK, pETC2QKST, pETC2O, and pETC2OH. To demonstrate the effect of the hairpin introduction, the decay profiles of the optimized PHA synthase mRNAs with or without the hairpin structure were determined via quantitative real-time PCR. Figure 1a showed the percentages of 


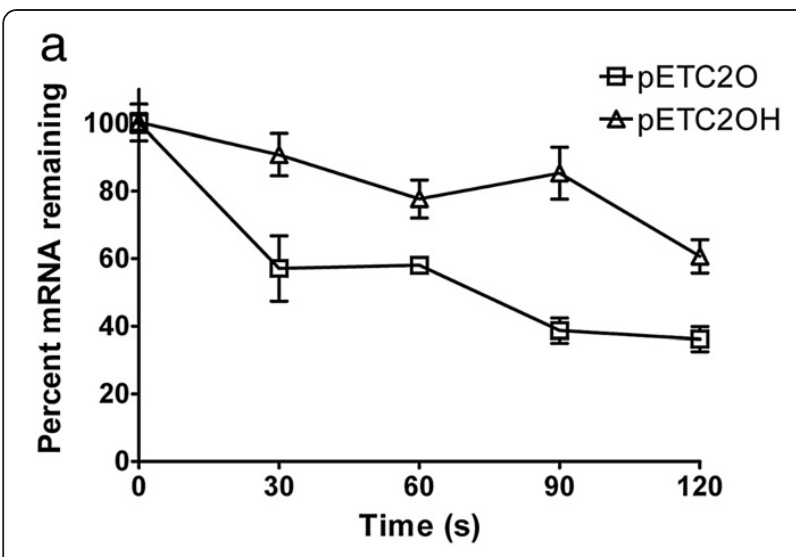

b

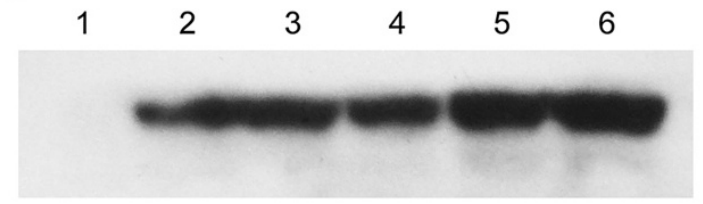

Figure 1 Gene expression profiles and western blot analysis of PhaC2 $2_{\mathrm{ps}} \mathrm{s}$ in recombinant $E$. coli harboring $\mathrm{pET}$-based plasmids. (a) The decay profiles of the transcripts of phaC2 $p_{s} \mathrm{O}$ and phaC2 $p_{5} \mathrm{OH}$ determined by quantitative RT-PCR. After adding rifampicin and incubating for $1 \mathrm{~min}$, samples were iced at different timed intervals. The relevant abundances of mRNA compared to the ompA mRNA abundance were determined by $\mathrm{qPCR}$, and the $y$ axis showed the percentages of the remaining mRNA at timed intervals. Experiments were carried out in triplicate. (b) Western blot analysis of the PHA synthase PhaC2 $p_{s}$ expressed in recombinant $E$. coli harboring PETbased plasmids. Lane 1 to 6 : crude extracts from recombinant $E$. coli harboring pET28a, pETC2, pETC2QK, pETC2QKST, pETC2O, and pETC2OH, respectively.

the remaining mRNA at different time intervals. The mRNA with the hairpin structure (expressed in pETC2OH) appeared to be more stable than the one without it (expressed in pETC2O), indicating the hairpin structure had contributed to an enhanced level of gene expression.

The PHA synthase expression levels were further examined by western blot analysis (Figure 1b). While the original PhaC2 $2_{\mathrm{Ps}}$, the mutants $\mathrm{PhaC} 2_{\mathrm{Ps}} \mathrm{QK}$ and $\mathrm{PhaC} 2{ }_{\mathrm{Ps}} \mathrm{QKST}$ were expressed with similar abundance, codon optimization of the gene significantly increased the protein expression level (lane 5). With hairpin structure inserted in front of the gene, the protein expression was further enhanced (lane 6).

\section{PHB accumulation in recombinant $E$. coli expressing optimized $\mathrm{PhaC} 2_{\mathrm{Ps}}$}

To test the functions of different $\mathrm{PhaC} 22_{\mathrm{Ps}} \mathrm{S}$ for PHB production in $E$. coli, a series of plasmids were constructed harboring $p h b A, p h b B$, and different $p h a C 2_{P S}$ genes (Table 1). The five plasmids were named pYC2, pYC2QK, pYC2QKST, pYC2O, and $\mathrm{pYC} 2 \mathrm{OH}$, harboring PHA synthase genes including the original phaC2 $2_{P_{S}}$, the two recombinants phaC2 ${ }_{P S} Q K$ and phaC2 ${ }_{P_{S}} Q K S T$, the codon optimized phaC $2_{P S} O$, and phaC $2_{P s} O$ with a hairpin coding region, respectively. The details are described in Methods. Other transcription and translation-related elements such as promoters and ribosome binding sites were maintained the same among those constructed plasmids to avoid differences resulting from those elements.

The five constructed plasmids were transformed into E. coli JM109 to evaluate their functions of PHB accumulation, respectively. The shake flask study was performed using these recombinants grown on MS medium supplemented with thiamine. When $20 \mathrm{~g} / \mathrm{l}$ gluconate was supplied as the sole carbon source, homopolymer PHB was synthesized under the catalysis of $\mathrm{PhaC} 22_{\mathrm{Ps}} \mathrm{S}$ after $48 \mathrm{~h}$ of cultivation (Figure 3). Shake flask experiment showed significant differences in $\mathrm{PHB}$ production and CDW among the recombinants (Figure 3 ). While native $\mathrm{PhaC} 2_{\mathrm{Ps}}$ only accumulated less than $2 \%$ PHB in cell dry weight (CDW) of $2.5 \mathrm{~g} / \mathrm{l}$, specific point mutagenesis of $\mathrm{PhaC} 2_{\mathrm{Ps}}$ increased $\mathrm{PHB}$ content to $2.4 \mathrm{wt} \%$ for $\mathrm{PhaC} 2{ }_{\mathrm{Ps}} \mathrm{QK}$ and $12 \mathrm{wt} \%$ for double mutated PhaC2 ${ }_{\mathrm{Ps}} \mathrm{QKST}$ (Figure 3). Subsequently, the codon optimization of PhaC $2_{\mathrm{Ps}} \mathrm{QKST}$ showed a significant improvement in enzyme activity indicated by the enhanced PHB accumulation to 20.4 wt\% CDW (Figure 3). The PhaC2 $2_{\mathrm{Ps}} \mathrm{QKST}$ with a hairpin structure that stabilized the mRNA further increased the $\mathrm{PHB}$ content to $30 \mathrm{wt} \%$. The series of $\mathrm{PhaC} 2 \mathrm{Ps}$ optimization achieved approximately 15 -fold improvement in PHB content in total, and the codon optimization and hairpin structure contributed approximately 2.6-fold. Along with the enhancement of PHA production, CDW was also increased from $2.5 \mathrm{~g} / \mathrm{l}$ to $3.4 \mathrm{~g} / \mathrm{l}$ in this process.

\section{Scl-mcl PHA production by recombinant $E$. coli}

In order to study their abilities of scl-mcl PHA production, the recombinant plasmids pYC2, pYC2QK, pYC2QKST, pYC2O, and $\mathrm{pYC} 2 \mathrm{OH}$ were transformed into E. coli LS5218, a FadR and AtoC (two regulators in fatty acid degradation) deficient strain [33]. The shake flask study was performed with these recombinant strains using MS medium supplied with $1 \mathrm{~g} / \mathrm{l}$ yeast extract. When cultured with $8 \mathrm{~g} / \mathrm{l}$ dodecanoate as a carbon source, the recombinant strains accumulated scl-mcl PHA with various concentrations and monomer compositions (Table 2). An obvious increase of PHA content from $0.81 \mathrm{wt} \%$ to $3.93 \mathrm{wt} \%$ (significance $\mathrm{p}<0.01$ ), along with a slight increase of CDW from $3.23 \mathrm{~g} / \mathrm{l}$ to $3.59 \mathrm{~g} / \mathrm{l}$ was observed. The recombinant harboring pYC2 could only accumulate $0.81 \mathrm{wt} \%$ PHA composed of 3HB, 3hydroxyoctanoate $(3 \mathrm{HO})$ and 3-hydroxydecanoate (3HD), while the recombinant harboring the double mutated PhaC2 $2_{\mathrm{Ps}} \mathrm{QKST}$ accumulated PHA up to $1.79 \mathrm{wt} \%$ with an enhanced $3 \mathrm{HB}$ molar ratio at $84 \mathrm{~mol} \%$, and 


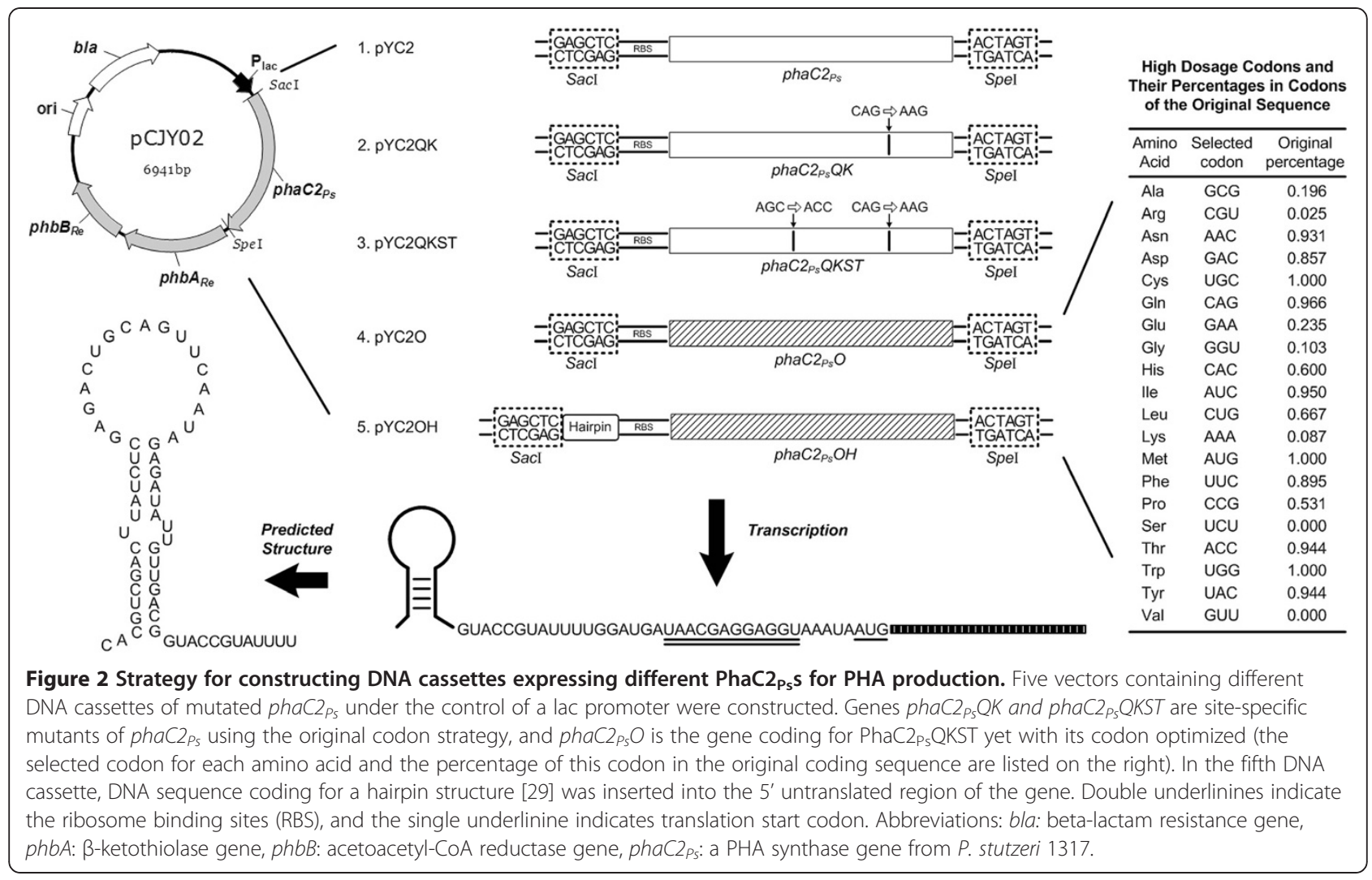

Table 1 Bacterial strains and plasmids

\begin{tabular}{|c|c|c|}
\hline Strains or plasmids & Relevant characteristics & Source or reference \\
\hline \multicolumn{3}{|l|}{ Strains } \\
\hline E. coli JM109 & $\begin{array}{l}\text { recA1, endA1, gyrA96, thi, hsdR17, supE44, relA1, } \Delta(\text { lac proAB }) / F^{\prime} \\
{\left[\operatorname{traD} 36, \operatorname{pro} A B^{+}, \operatorname{lac}^{9} \text { lacZ } \triangle \mathrm{M} 15\right]}\end{array}$ & TaKaRa (Dalian, China) \\
\hline E. coli LS5218 & atoc fadR & {$[37]$} \\
\hline \multicolumn{3}{|l|}{ Plasmids } \\
\hline pBHR69 & pBluscript SK- derivative, $p h b A_{R e}$ and $p h b B_{R e}$ cloned from R. eutropha & [38] \\
\hline pCJY02 & $\begin{array}{l}\text { pBluscript SK- derivative, phb } A_{R e} \text { and phbB } B_{R e} \text { cloned from R. eutropha phaC2 } p_{s} \\
\text { cloned from P. stutzeri } 1317\end{array}$ & [39] \\
\hline pSXWQK & pBBR1MCS-2 derivative, mutated phaC2 $p_{s}$ Gln $482 \rightarrow$ Lys $(C A G \rightarrow A A G)$ & [20] \\
\hline pSXWQKST & $\begin{array}{l}\text { pBBR1MCS-2 derivative, double mutated phaC2ps Ser326 } \rightarrow \text { Thr } \\
(A G C \rightarrow A C C) \text { Gln482 } \rightarrow \text { Lys }(C A G \rightarrow A A G)\end{array}$ & [20] \\
\hline pETC2 & Wild type phaC2 ${ }_{p_{s}}$ inserted into pET28a & This study \\
\hline pETC2QK & Mutated phaC2 $p_{s}$ inserted into pET28a & This study \\
\hline pETC2QKST & Double mutated phaC2ps inserted into pET28a & This study \\
\hline pETC2O & Codon optimized phaC2 $p_{5} Q K S T$ inserted into pET28a & This study \\
\hline $\mathrm{pETC2OH}$ & Codon optimized phaC2 $p_{s} Q K S T$ with hairpin sequence inserted into pET28a & This study \\
\hline pYC2 & pBHR69 derivative, wild type phaC2 $p_{s}$ of $P$. stutzeri 1317, plus $p h b A_{R e}$ and $p h b B_{R e}$ & This study \\
\hline PYC2QK & Mutated phaC2 $p_{s}$ inserted into pBHR69 & This study \\
\hline pYC2QKST & Double mutated phaC2 $p_{s}$ inserted into pBHR69 & This study \\
\hline pYC2O & Codon optimized phaC2 $p_{5} Q K S T$ inserted into pBHR69 & This study \\
\hline $\mathrm{pYC2OH}$ & Codon optimized phaC2 $p_{s}$ QKST with hairpin sequence inserted into pBHR69 & This study \\
\hline
\end{tabular}




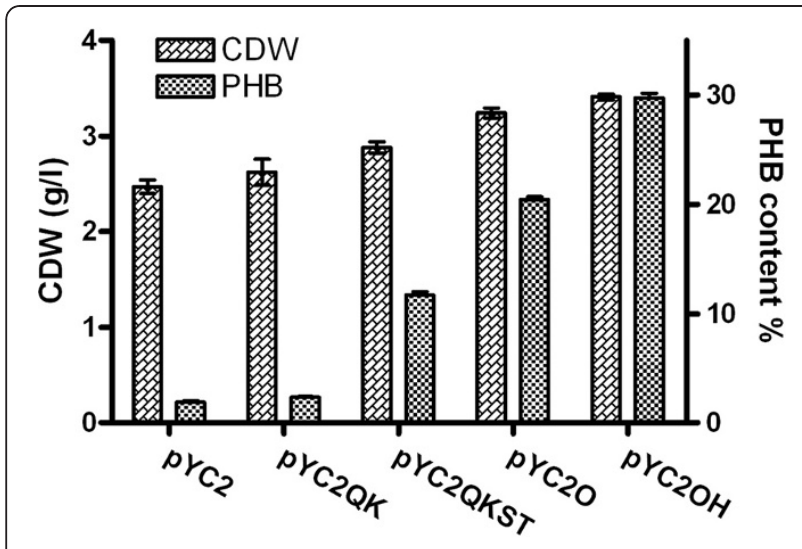

Figure 3 PHB accumulation of E. coli JM109 expressing different $\mathrm{PhaC} 2_{\mathrm{Ps}} \mathrm{s}$ using gluconate as carbon source. Data represent results for three independent experiments \pm standard deviations. The cultivation was conducted in $500 \mathrm{ml}$ shake flasks each having $50 \mathrm{ml}$ MS medium containing $20 \mathrm{~g} / \mathrm{l}$ gluconate and $100 \mathrm{mg} / \mathrm{l}$ thiamine. IPTG $(0.1 \mathrm{~mol} / \mathrm{l})$ was used as an inducing agent for lac promoter and was added at $6 \mathrm{~h}$ after inoculation. After $48 \mathrm{~h}$ cultivation, strains harboring $\mathrm{pYC2OH}$ showed the highest CDW and PHB content (30 wt \%, approximately 16 -fold of the strains harboring PY(2), and the effect of codon optimization and hairpin stabilization was about 2.6-fold compared to the strain harboring pYC2QKST $(p<0.01)$.

3-hydroxydodecanoate (3HDD) was also detected. Furthermore, in the case of the codon optimized $\mathrm{PhaC} 2_{\mathrm{Ps}} \mathrm{O}$, the recombinant strain accumulated $3.40 \mathrm{wt} \%$ PHA with monomers including 3HB, 3-hydroxyhexanoate (3HHx), $3 \mathrm{HO}, 3 \mathrm{HD}$ and 3HDD. Among those recombinants, the one harboring $\mathrm{pYC} 2 \mathrm{OH}$ accumulated the highest PHA content of $3.93 \mathrm{wt} \%$, in which the molar ratios of $3 \mathrm{HB}$, $3 \mathrm{HHx}, 3 \mathrm{HO}, 3 \mathrm{HD}$ and 3HDD were 39.59, 5.80, 6.91, 45.46 and 2.24 , respectively.

To further investigate the effect of precursor supply in scl-mcl PHA production, different concentrations of gluconate were added as an additional carbon source to the recombinant $E$. coli LS5218 harboring plasmid pYC2OH. A better growth and higher PHA accumulation were observed when $5 \mathrm{~g} / \mathrm{l}$ or $10 \mathrm{~g} / \mathrm{l}$ gluconate was added compared to $20 \mathrm{~g} / \mathrm{l}$ (Table 3), indicating a suitable balance between cell growth and PHA accumulation in this condition. $3 \mathrm{HB}$ fraction ranging from $52 \%$ to $96 \%$ in the polymers increased as more gluconate was provided (Table 3).

\section{Discussion}

With the development of synthetic biology, many functional modules are designed to be heterologously expressed in a host strain, and thus efficient and sometimes precise expression of a specific enzyme is generally required to meet the demand of coordination among multiple modules [34]. There are many possibilities to adjust expression levels of proteins in different situations, and codon optimization is generally considered a universal means to control or enhance heterologous protein expression [31,32]. Recent development in DNA synthesis and sequencing allows the rapid and accurate synthesis of large amount of DNA constructs at a lower cost, providing more accessibility to optimizing codon usage of heterologously expressed genes and to screening for suitable expression levels [35]. The "one amino acid-one codon" optimization strategy was employed in this study. PHB accumulation studies indicated that the mutagenesis and optimization of PHA synthase $\mathrm{PhaC} 2_{\mathrm{Ps}}$ cloned from P. stutzeri 1317 significantly enhanced the synthase polymerization activity, and thus promoted PHB synthesis (Figure 3). It was previously reported that $\mathrm{PhaC} 2_{\mathrm{Ps}}$ could achieve up to $40 \mathrm{wt}$ $\%$ PHB accumulation when expressed in $R$. eutropha PHB-4 $[19,20]$. However, when expressed in E. coli, this PHA synthase could only accumulate trace amount of PHB (Figure 3). The series of site-specific mutagenesis of this synthase $\mathrm{PhaC} 22_{\mathrm{Ps}}$ was reported to achieve higher PHA accumulation and $3 \mathrm{HB}$ fraction in $R$. eutropha PHB-4 [20], and the same phenomenon could be observed when the mutated enzymes were expressed in E. coli (Figure 3). The double mutant $\mathrm{PhaC} 2_{\mathrm{Ps}} \mathrm{QKST}$

Table $2 \mathrm{Scl}$ and mcl PHA production by E. coli LS5218 harboring different PhaC2 ${ }_{\mathrm{Ps}}{ }^{a}$

\begin{tabular}{|c|c|c|c|c|c|c|c|c|}
\hline \multirow[t]{2}{*}{ Plasmid } & \multirow{2}{*}{$\begin{array}{c}\mathrm{CDW}^{b} \\
(\mathrm{~g} / \mathrm{l})\end{array}$} & \multirow{2}{*}{$\begin{array}{l}\text { PHA content }{ }^{c} \\
(w t \%)\end{array}$} & \multirow{2}{*}{$\begin{array}{l}\text { Significant } \\
\text { difference }^{d}\end{array}$} & \multicolumn{5}{|c|}{ PHA composition (mol \%) } \\
\hline & & & & $3 \mathrm{HB}$ & $3 \mathrm{HHx}$ & $3 \mathrm{HO}$ & $3 \mathrm{HD}$ & $3 \mathrm{HDD}$ \\
\hline pYC2 & $3.23 \pm 0.03$ & $0.81 \pm 0.06$ & - & $32.35 \pm 1.16$ & $\mathrm{ND}^{f}$ & $10.61 \pm 2.84$ & $57.04 \pm 3.66$ & ND \\
\hline pYC2QK & $3.15 \pm 0.12$ & $1.41 \pm 0.06$ & 0.019 & $46.00 \pm 2.84$ & ND & $6.90 \pm 0.53$ & $47.10 \pm 2.82$ & ND \\
\hline pYC2QKST & $3.13 \pm 0.06$ & $1.79 \pm 0.10$ & 0.008 & $41.59 \pm 3.43$ & ND & $6.28 \pm 0.56$ & $49.93 \pm 2.77$ & $2.21 \pm 0.09$ \\
\hline pYC2O & $3.39 \pm 0.04$ & $3.40 \pm 0.05$ & 0.004 & $39.49 \pm 0.36$ & $5.93 \pm 0.05$ & $6.97 \pm 0.06$ & $45.33 \pm 0.24$ & $2.27 \pm 0.02$ \\
\hline $\mathrm{pYC2OH}$ & $3.59 \pm 0.11$ & $3.93 \pm 0.11$ & 0.004 & $39.59 \pm 0.23$ & $5.80 \pm 0.12$ & $6.91 \pm 0.12$ & $45.46 \pm 0.27$ & $2.24 \pm 0.07$ \\
\hline
\end{tabular}

${ }^{a}$ Cells were cultivated at $37^{\circ} \mathrm{C}$ and $200 \mathrm{rpm}$ for $48 \mathrm{~h}$ as described in "Methods". $8 \mathrm{~g} / \mathrm{l}$ dodecanoate were added to the MS medium. Three parallel experiments were conducted for each datum.

b CDW: cell dry weight.

c PHA content: PHA contents are given as mass percentage of CDW.

d Significant difference: $\mathrm{p}$ value calculated by student's t-test, indicating the significant difference between the respective and the previous PHA contents.

e 3HB, 3-hydroxybutyrate; 3HHx, 3-hydroxyhexanoate; 3HO, 3-hydroxyoctanoate; 3HD, 3-hydroxydecanoate; 3HDD, 3-hydroxydodecanoate.

${ }^{f} \mathrm{ND}$ : not detected. 
Table $3 \mathrm{Scl}$ and mcl PHA accumulation by recombinant E. coli LS5218 harboring pYC2OH grown in mixtures of gluconate and dodecanoate ${ }^{a}$

\begin{tabular}{|c|c|c|c|c|c|c|c|}
\hline \multirow{2}{*}{$\begin{array}{l}\text { Concentration of } \\
\text { gluconate }(g / l)\end{array}$} & \multirow[t]{2}{*}{ CDW (g/l) } & \multirow[t]{2}{*}{ PHA content (wt\%) } & \multicolumn{5}{|c|}{ PHA composition (mol \%) } \\
\hline & & & $3 \mathrm{HB}$ & $3 \mathrm{HHx}$ & $3 \mathrm{HO}$ & $3 \mathrm{HD}$ & $3 \mathrm{HDD}$ \\
\hline 5 & $3.73 \pm 0.02$ & $4.18 \pm 0.16$ & $52.39 \pm 3.40$ & $5.16 \pm 0.54$ & $20.24 \pm 1.11$ & $14.89 \pm 1.75$ & $7.32 \pm 0.70$ \\
\hline 10 & $3.47 \pm 0.33$ & $3.99 \pm 0.35$ & $70.11 \pm 3.12$ & $4.50 \pm 0.31$ & $14.16 \pm 0.72$ & $7.01 \pm 0.62$ & $4.22 \pm 0.08$ \\
\hline 20 & $2.10 \pm 0.10$ & $3.36 \pm 0.18$ & $96.33 \pm 0.78$ & ND & $3.67 \pm 0.78$ & ND & ND \\
\hline
\end{tabular}

${ }^{a}$ Cells were cultivated at $37^{\circ} \mathrm{C}$ and $200 \mathrm{rpm}$ for $48 \mathrm{~h}$ as described in "Methods". Mixed carbon sources consisting of different concentrations of gluconate and $8 \mathrm{~g} / \mathrm{l}$ dodecanoate were added to the MS medium. Three parallel experiments were conducted for each datum.

could enhance PHB accumulation approximately 6-fold compared to the wild type did, and this was partially due to the altered substrate-specificity [20]. Another 1.7-fold of PHB accumulation was observed in the case of codon-optimized synthase $\mathrm{PhaC} 2_{\mathrm{Ps}} \mathrm{O}$ (Figure 3). Since the specificity was not altered compared to PhaC2 ${ }_{\text {Ps }} \mathrm{QKST}$ (the amino acids sequence was exactly the same), this result indicated that the increased PHB content was completely due to the enhancement of synthase expression.

The FadR-deficient strain E. coli LS5218 was used as the host to evaluate the scl-mcl PHA production driven by different $\mathrm{PhaC} 2_{\mathrm{Ps}_{\mathrm{s}}} \mathrm{s}$. When grown on MS medium supplemented with $8 \mathrm{~g} / \mathrm{l}$ dodecanoate, all five recombinants harboring different plasmids could accumulate scl-mcl PHA (Table 2). Yet for strains harboring pYC2 or pYC2QK, only $3 \mathrm{HB}, 3 \mathrm{HO}$ and $3 \mathrm{HD}$ monomers were detected. Compared to the wild type PhaC $2_{\mathrm{Ps}}$, the two site-specific mutants $\mathrm{PhaC} 2_{\mathrm{Ps}} \mathrm{QK}$ and $\mathrm{PhaC} 2_{\mathrm{Ps}} \mathrm{QKST}$ increased PHA content and thus also the cell dry weight. Simultaneously, the substrate specificity was altered as a higher fraction of $3 \mathrm{HB}$ was observed, which was consistent with the previous report [20]. However, the overall PHA content was relatively low (1.79 wt\%). After codon optimization of phaC2 $2_{P S} Q K S T$, the PHA content was significantly increased to $3.40 \mathrm{wt} \%$ and various $\mathrm{PHA}$ monomers were found including $3 \mathrm{HB}, 3 \mathrm{HHx}, 3 \mathrm{HO}$, $3 \mathrm{HD}$ and 3HDD. Particularly, the 3HB monomer fraction was reduced slightly compared to the situation of PHA synthesis by PhaC2 $2_{\mathrm{Ps}_{\mathrm{s}}} \mathrm{QKST}$ (Table 2), indicating that the monomer composition relies on multiple factors including the substrate specificity, the polymerization efficiency and the precursor supply. Both the PHB and scl-mcl PHA productions by the optimized PhaC2 $2_{\mathrm{Ps}} \mathrm{QKST}$ verified that the codon optimization strategy worked well in this condition (Figure 3 and Table 2). The replacement of rare codons such as AGG (Arg) and CUA (Leu) led to an significant increase in PHA production, indicating that the expression level of the key enzyme PHA synthase was strongly enhanced. It should be mentioned that there are other algorithms for codon optimization, and their functions on this specific case remain to be explored. It is expected that further optimization on PHA synthases can lead to wider substrate specificity and higher expression level, allowing the precise control of PHA polymerization.

Altering expression related factors such as promoters, ribosome binding sites, and mRNA stabilizers are possibilities to change the transcription and translation level of key PHA synthesis enzymes. In this study, a hairpin structure pHP17 which was reported to increase the half life of mRNA up to $19.8 \mathrm{~min}$ [29] was inserted in the 5' UTR of $p h a C 2_{P s} O$, and it contributed another 1.5-fold in PHB accumulation (Figure 3), demonstrating that the degradation of the mRNA of phaC2 $2_{P S}$ is a significant factor that affects PHA accumulation. In the case of scl-mcl PHA production, the contribution of the hairpin structure was also significant $(p<0.01)$. However, since the main function of this structure is to increase mRNA stability, it is possible that the effect of a hairpin structure is largely dependent on the expression profiles in different conditions.

For the last version of the optimized $\mathrm{PhaC} 2_{\mathrm{Ps}}$ (codon optimized and hairpin inserted) the effect of different precursor supply situations to the monomer compositions of scl-mcl PHA was investigated. Compared to the presence of $20 \mathrm{~g} / \mathrm{l}$ gluconate along with $8 \mathrm{~g} / \mathrm{l}$ dodecanoate (Table 3), E. coli LS5218 harboring pYC2OH could accumulate slightly more PHA when $5 \mathrm{~g} / \mathrm{l}$ gluconate or $10 \mathrm{~g} / \mathrm{l}$ were added, and the CDW was also higher. This was probably due to a better balance that could be reached between cell growth and PHA accumulation under low gluconate concentration, which allowed proper coordination with the specificity and expression level of the PHA synthase. On the other hand, monomer compositions can be adjusted by providing different ratios of precursors coming from multiple metabolism pathways. Since E. coli has been well investigated and is relatively easy for genetic integration, we can expect efficient scl-mcl PHA production from unrelated carbon sources if precursor supplying pathways are introduced, and precise control of the carbon flux through these pathways would lead to PHA production with desired compositions. Furthermore, expression cassettes with high efficiency is often required for chromosomal expression since it is generally more difficult compared to 
plasmid system, therefore this investigation provides an optimized PHA synthase which may contribute to plasmid-free PHA production in E. coli in the future.

\section{Conclusions}

In summary, a series of optimization strategies were applied on the PHA synthase PhaC2 $2_{\mathrm{Ps}}$ from P. stutzeri 1317, which is a PHA synthase with wide substrate specificities, to optimize its heterologous expression and PHA production in E. coli. The codon optimization and hairpin structure in the 5 -UTR of the mRNA were effective for optimizing PhaC2 2 ss expression, and both the $\mathrm{PHB}$ and scl-mcl PHA production levels were significantly increased. The results indicated that these strategies provide a good opportunity for future PHA production with optimized yield and composition.

\section{Methods}

Optimization of the coding sequence and transcription region of target $\mathrm{PhaC}$ gene

For codon bias optimization, "one amino acid-one codon" strategy [36] was employed in this study to obtain an optimized translational region of the target gene. Codon preference in E. coli $\mathrm{K}-12$ was selected and the codons of predicted highly expressed genes were chosen to replace rare ones. A hairpin structure which was reported to be able to increase mRNA stability [29] was introduced in the 5' UTR of the mRNA for the target gene. The entire coding sequence of the optimized gene along with the hairpin region [GenBank: JX082171] was synthesized by Shanghai Qinglan Biotech Co., Ltd.

\section{Bacterial strains, plasmids, and general procedures for DNA manipulation}

The main bacterial strains and plasmids used in this study are listed in Table 1. E. coli Trans1-T1 (Transgen) strain was used for plasmids construction mentioned in this study. E. coli JM109 and E. coli LS5218 [37] were used for evaluating the expression of the PHA synthase $\mathrm{PhaC} 2_{\mathrm{Ps}}$ and accumulating PHA with different compositions.

Plasmids related to PHA accumulation were a highcopy plasmid pBHR69 derivatives harboring $p h b A$ and phbB (originally cloned from $R$. eutropha H16) encoding $\beta$-ketothiolase and acetoacetyl-CoA reductase, respectively [38], together with different mutated phaC $2_{P s}$ genes. For plasmid constructions, genes were subcloned using standard PCR procedures, digested by respective restriction enzymes, and then ligated into the backbone of pBHR69. Specifically, DNA fragments coding for the optimized $\mathrm{PhaC} 2{ }_{\mathrm{Ps}} \mathrm{QKST}$ with (termed phaC2 ${ }_{P s} \mathrm{OH}$ ) or without $\left(\right.$ phaC $\left.2_{P S} O\right)$ a hairpin sequence were amplified using primer pairs YXXHF/YXXR or YXXF/YXXR (Table 4). Subsequently, the two fragments were digested by $\mathrm{SacI}$ and SpeI, purified via gel electrophoresis, and finally inserted into pBHR69. The resulting plasmids were named pYC2OH and pYC2O, respectively. Similarly, genes encoding the wild type $\mathrm{PhaC} 2_{\mathrm{Ps}}$ and two site-specific mutants PhaC2 $2_{\mathrm{Ps}} \mathrm{QK}$ and PhaC2 ${ }_{\mathrm{Ps}} \mathrm{QKST}$ were subcloned from plasmids pCJY02 [39], pSXWQK and pSXWQKST [20] using primer pair 02SF and 02SR. These DNA fragments were digested by the same endonucleases and then ligated to pBHR69 backbone, leading to plasmids pYC2, pYC2QK and pYC2QKST, respectively. The constructs were verified by PCR using primer Tes02F and Tes02R followed by sequencing verification. To assess the effect of

Table 4 Oligonucleotide sequences

\begin{tabular}{|c|c|}
\hline \multicolumn{2}{|c|}{ Primers for construction and verification of plasmids } \\
\hline pET-F & TAAAGGGAACAAAAGCTGGAGCT \\
\hline pET-R & GCCAAGCTTACGGATGTGAACGTAGGTAC?? \\
\hline pET-HF & GCCAAGCTTACGGATGTGAACGTAGGTAC \\
\hline qPCR-OmpA-S & GTATGGCGTGCAGACACTAA \\
\hline qPCR-OmpA-A & ACTGGTATTCCAGACGGGTAG \\
\hline qPCR-phaC-S & TGATCCAGTACCGTCCGATGT \\
\hline qPCR-phaC-A & GAAGACAGACCCCATTCACG \\
\hline 02SF & 5'- ATTGAGCTCGTATTITGGATGATAACGAGGAGGTAAATAATGCGAGACAAGCCCAATAG ${ }^{a}$ \\
\hline 02SR & 5'- AATTACTAGTCCTCAGCGGATATGCACGTAGG -3' \\
\hline YXXHF & 5'- ATAATTGAGCTCCACGTCGACTTATCTCGAGACTG -3' \\
\hline YXXF & 5'- ATAATTGAGCTCGTATTTTGGATGATAACGAGGAG -3' \\
\hline YXXR & 5'- ATAATTACTAGTCCTTAACGGATGTGAACGTAGGT -3' \\
\hline Tes02F & 5'- ATTCTGTGGATAACCGTATTACC -3' \\
\hline Tes02R & 5'- GCACACCTTGTTGATGGTCATGG -3' \\
\hline
\end{tabular}

aases underlined indicate Sacl and Spel restriction sites in the forward and reversed primers, respectively. 
the optimization strategies on mRNA decay and gene expression, $\mathrm{pET}$-based series plasmids were constructed: the five phaC $2_{P S}$ genes were cloned using primer pairs pET-F/R or pET-HF/R, digested by SacI and HindIII, purified via gel electrophoresis, and finally inserted into pET28a. Restriction enzymes were purchased from Fermentas (China). Plasmids were sequenced by Biosune (Beijing, China).

\section{Analysis of the mRNA decay profiles by quantitative real-time PCR}

The recombinant cells (E. coli JM109 harboring pETC2O or pETC2OH) were cultured in LB medium. When OD600 reached 0.2 , isopropyl $\beta$-D-1-thiogalactopyranoside (IPTG, $0.1 \mathrm{~mol} / \mathrm{l}$ ) were added and cells were cultured for another $2 \mathrm{~h}$. Rifampicin was added to a final concentration of $50 \mu \mathrm{g} / \mathrm{ml}$ to inhibit RNA synthesis. After $1 \mathrm{~min}$ of incubation, culture samples were iced at timed intervals. Total RNA was isolated from each sample using the E.Z.N.A. ${ }^{\circledR}$ Bacterial RNA Kit (Omega Bio-tek). The purity and concentration of RNA were checked using a Nanodrop 2000 spectrophotometer (Thermo Fisher Scientific). Following cDNA synthesis was performed using the Quantscript RT Kit (Tiangen).

The mRNA decay profiles were determined by realtime PCR using the cDNA samples as the templates. The $о m p A$ gene was selected as the housekeeping gene. The real-time PCRs were performed using the SuperReal PreMix (SYBR Green) kit (Tiangen) with MxPro 3000P (Agilent Technology). The primers for real-time PCR are listed in Table 1, and the reaction condition was as follows: $95^{\circ} \mathrm{C}$ for $5 \mathrm{~min}$; $95^{\circ} \mathrm{C}$ for $20 \mathrm{~s}, 55^{\circ} \mathrm{C}$ for $30 \mathrm{~s}$, and $72^{\circ} \mathrm{C}$ for $30 \mathrm{~s}$ for 40 cycles.

\section{Western blot analysis}

The recombinant strains were cultivated in LB medium with IPTG $(0.1 \mathrm{~mol} / \mathrm{l})$ and then harvested by centrifugation. After resuspending the cells in PBS buffer, crude extracts were obtained by disrupting the cells with sonication. The concentrations of total proteins were determined with a BCA protein assay kit (Vigorous). Proteins $(10 \mu \mathrm{g})$ in crude extracts were separated by sodium dodecyl sulfatepolyacrylamide gel electrophoresis (SDS-PAGE). Western blot analysis of $\mathrm{PhaC} 22_{\mathrm{Ps}}$ was carried out using anti His-tag mouse monoclonal antibodies (CW Biotech). Horseradish peroxidase (HRP)-conjugated anti-mouse antibodies (Santa Cruz Biotechnology) were used as a secondary antibody.

\section{Medium and culture conditions}

Different strains of $E$. coli were grown in LB medium or on LB agar plates at $37^{\circ} \mathrm{C}$. Antibiotics including ampicilin $(100 \mathrm{mg} / \mathrm{ml})$ and kanamycin $(50 \mathrm{mg} / \mathrm{ml})$ were added when necessary. Antibiotics were purchased from Sigma (Beijing, China). For PHA accumulation, shake flask experiments were carried out in a rotary shaker (NBS, Series 25D, New Brunswick, NJ, USA) at $200 \mathrm{rpm}$ and $37^{\circ} \mathrm{C}$ using $500-\mathrm{ml}$ conical flasks each containing $50 \mathrm{ml}$ of medium. $20 \mathrm{~g} / \mathrm{l}$ gluconate was used for the evaluation of optimized PhaC2 $2_{\mathrm{Ps}}$ for enhanced poly-3hydroxybutyrate (PHB) synthesis, and $8 \mathrm{~g} / \mathrm{l}$ dodecanoate plus $0 \mathrm{~g} / \mathrm{l}, 5 \mathrm{~g} / \mathrm{l}, 10 \mathrm{~g} / \mathrm{l}$, or $20 \mathrm{~g} / \mathrm{l}$ gluconate was added as carbon sources in the case of scl-mcl PHA production. To achieve better utilization of dodecanoate, the flasks were shaken at $60 \mathrm{rpm}, 45^{\circ} \mathrm{C}$ immediately after sterilization in a rotary shaker until dodecanoate was scattered. Cells of E. coli JM109 or LS5218 were first cultured in LB medium for $12 \mathrm{~h}$ and then transferred to mineral salt (MS) medium containing different carbon sources at an inoculation volume of $4 \%$ for $48 \mathrm{~h}$. The MS medium contained (per liter) $9.0 \mathrm{~g} \mathrm{Na}_{2} \mathrm{HPO}_{4} \cdot 12 \mathrm{H}_{2} \mathrm{O}, 1.5 \mathrm{~g} \mathrm{KH}_{2} \mathrm{PO}_{4}, 1.0 \mathrm{~g}\left(\mathrm{NH}_{4}\right)_{2} \mathrm{SO}_{4}$, $0.4 \mathrm{~g} \mathrm{MgSO}_{4} \cdot 7 \mathrm{H}_{2} \mathrm{O}$ and $2 \%(\mathrm{v} / \mathrm{v})$ trace element solution as described in previous studies [40]. $100 \mathrm{mg} / \mathrm{l}$ thiamine was added into the MS medium when $E$. coli JM109 was used since this strain is thiamine-deficient. For scl-mcl PHA production, $1 \mathrm{~g} / \mathrm{l}$ yeast extract was added for the culture of $E$. coli $\mathrm{LS} 5218$. IPTG $(0.1 \mathrm{~mol} / \mathrm{l})$ was used as an inducing agent for lac promoter and was added at $6 \mathrm{~h}$ after inoculation.

\section{Gas chromatography (GC) analysis of PHA in dry cells}

Cell dry weight (CDW) was evaluated by harvesting $30 \mathrm{ml}$ cell cultures, centrifuged at $10,000 \mathrm{rpm}$ for $10 \mathrm{~min}$ and then washed with distilled water when gluconate was added as sole carbon source. In the case of scl-mcl PHA production using dodecanoate as a carbon source, cells were washed twice with ethanol before washed with distilled water. CDW was measured after vacuum lyophilization (free of the remaining $\mathrm{C} 12$ carbon sources). The lyophilized cells and standard PHA samples were subjected to methanolysis in chloroform at $100^{\circ} \mathrm{C}$ for $4 \mathrm{~h}$ in the presence of $3 \%(\mathrm{v} / \mathrm{v}) \mathrm{H}_{2} \mathrm{SO}_{4}$ to prepare samples for gas chromatography (GC) (SHIMADZU GC-2014C, Kyoto, Japan) equipped with 30-m HP-5 capillary column [41]. PHA contents were determined by analyzing the $\mathrm{GC}$ data.

\section{Statistical analysis}

For statistical analysis, three parallel experiments were conducted and data collected were evaluated by mean \pm SD. Student's two-tailed t-test was performed to determine the significance of differences $\left({ }^{* * *}: \mathrm{p}<0.01,{ }^{*}: \mathrm{p}<0.05\right)$.

\section{Competing interests}

The authors declare that they have no competing interests.

\section{Authors' contributions}

XG examined the mRNA stabilities and protein expression levels, performed the shake flask experiments and drafted the manuscript. XXY carried out the molecular manipulations and performed the preliminary shake flask experiments. ZYS designed the experiment and provide suggestions. YYG 
participated in plasmids construction. XWS carried out site-specific mutagenesis. JCC, QW and GQC supervised the study. All authors read and approved the final manuscript.

\section{Acknowledgements}

This research was financially supported by the 973 Basic Research Fund (Grant No. 2012CB725201 to GQC and Grant No. 2012CB725204 to QW), the National High Tech Suporting Grants (Project No. 2012BAD32B02 to JCC) and the National Natural Science Foundation of China (Grant No. 31170099 and Grant No. 31170940). We are grateful to Dr. A. Steinbüchel of the University of Münster, Germany, for the generous donation of the plasmid pBHR69.

\section{Author details}

${ }^{1}$ MOE Key Lab of Bioinformatics, Department of Biological Science and Biotechnology, School of Life Science, Tsinghua-Peking Center for Life Sciences, Tsinghua University, Beijing 100084, China. ${ }^{2}$ Synthenome.com, Dingley Village, Melbourne, VIC 3172, Australia. ${ }^{3}$ Center for Nano and Micro Mechanics, Tsinghua University, Beijing 100084, China.

Received: 30 June 2012 Accepted: 12 September 2012

Published: 14 September 2012

\section{References}

1. Gao X, Chen JC, Wu Q, Chen GQ: Polyhydroxyalkanoates as a source of chemicals, polymers, and biofuels. Curr Opin Biotechnol 2011, 22:768-774

2. Chen GQ, Patel MK: Plastics derived from biological sources: present and future: a technical and environmental review. Chem Rev 2012, 112:2082-2099.

3. Tripathi L, Wu LP, Chen J, Chen GQ: Synthesis of Diblock copolymer poly3-hydroxybutyrate-block-poly-3-hydroxyhexanoate [PHB- $b$-PHHx] by a beta-oxidation weakened Pseudomonas putida KT2442. Microb Cell Fact 2012, 11:44.

4. Zhou XY, Yuan XX, Shi ZY, Meng DC, Jiang WJ, Wu LP, Chen JC, Chen GQ: Hyperproduction of poly(4-hydroxybutyrate) from glucose by recombinant Escherichia coli. Microb Cell Fact 2012, 11:54.

5. Zhang S, Wang ZH, Chen GQ: Microbial polyhydroxyalkanote synthesis repression protein PhaR as an affinity tag for recombinant protein purification. Microb Cell Fact 2010, 9:28

6. Wang ZH, Ma P, Chen J, Zhang J, Chen CB, Chen GQ: A transferable heterogeneous two-hybrid system in Escherichia coli based on polyhydroxyalkanoates synthesis regulatory protein PhaR. Microb Cell Fact 2011, 10:21.

7. Hazer B, Steinbüchel A: Increased diversification of polyhydroxyalkanoates by modification reactions for industrial and medical applications. Appl Microbiol Biotechnol 2007, 74:1-12.

8. Chen GQ: A microbial polyhydroxyalkanoates (PHA) based bio- and materials industry. Chem Soc Rev 2009, 38:2434-2446.

9. Steinbüchel A, Lutke-Eversloh T: Metabolic engineering and pathway construction for biotechnological production of relevant polyhydroxyalkanoates in microorganisms. Biochem Eng J 2003, 16:81-96.

10. Doi $Y$, Kitamura S, Abe $\mathrm{H}$ : Microbial synthesis and characterization of poly (3-hydroxybutyrate-co-hydroxyhexanoate). Macromolecules 1995, 28:4822-4828.

11. Eggink G, de Waard P, Huijberts GN: Formation of novel poly (hydroxyalkanoates) from long-chain fatty acids. Can J Microbiol 1995, 41(Suppl 1):14-21.

12. Chen: Plastics from Bacteria: Natural Functions and Applications. Germany: Heidelberg; 2010.

13. Matsusaki $H$, Abe $H$, Doi Y: Biosynthesis and properties of poly(3hydroxybutyrate-co-3-hydroxyalkanoates) by recombinant strains of Pseudomonas sp. 61-3. Biomacromolecules 2000, 1:17-22.

14. Sudesh K, Abe H, Doi Y: Synthesis, structure and properties of polyhydroxyalkanoates: biological polyesters. Prog Polym Sci 2000, 25:1503-1555.

15. Jian J, Li ZJ, Ye HM, Yuan MQ, Chen GQ: Metabolic engineering for microbial production of polyhydroxyalkanoates consisting of high 3hydroxyhexanoate content by recombinant Aeromonas hydrophila. Bioresour Technol 2010, 101:6096-6102.
16. Normi YM, Hiraishi T, Taguchi S, Sudesh K, Najimudin N, Doi Y: Site-directed saturation mutagenesis at residue F420 and recombination with another beneficial mutation of Ralstonia eutropha polyhydroxyalkanoate synthase. Biotechnol Lett 2005, 27:705-712.

17. Loo CY, Lee WH, Tsuge T, Doi Y, Sudesh K: Biosynthesis and characterization of poly(3-hydroxybutyrate-co-3-hydroxyhexanoate) from palm oil products in a Wautersia eutropha mutant. Biotechnol Lett 2005, 27:1405-1410.

18. Tsuge T, Watanabe S, Sato S, Hiraishi T, Abe H, Doi Y, Taguchi S: Variation in copolymer composition and molecular weight of polyhydroxyalkanoate generated by saturation mutagenesis of Aeromonas caviae PHA synthase. Macromol Biosci 2007, 7:846-854.

19. Chen JY, Song G, Chen GQ: A lower specificity PhaC2 synthase from Pseudomonas stutzeri catalyses the production of copolyesters consisting of short-chain-length and medium-chain-length 3-hydroxyalkanoates. Antonie Van Leeuwenhoek 2006, 89:57-167.

20. Shen XW, Shi ZY, Song G, Li ZJ, Chen GQ: Engineering of polyhydroxyalkanoate (PHA) synthase $\mathrm{PhaC} 2 \mathrm{Ps}_{\mathrm{s}}$ of $P$ seudomonas stutzeri via site-specific mutation for efficient production of PHA copolymers. Appl Microbiol Biotechnol 2011, 91:655-665.

21. Dellomonaco C, Fava F, Gonzalez R: The path to next generation biofuels: successes and challenges in the era of synthetic biology. Microb Cell Fact 2010, 9:3.

22. Steinbüchel A, Fuchtenbusch B, Gorenflo V, Hein S, Jossek R, Langenbach S, Rehm BHA: Biosynthesis of polyesters in bacteria and recombinant organisms. Polym Degrad Stabil 1998, 59:177-182.

23. Park SJ, Lee SY: Biosynthesis of poly(3-hydroxybutyrate-co-3hydroxyalkanoates) by metabolically engineered Escherichia coli strains. Appl Biochem Biotechnol 2004, 113:335-346.

24. Matsumoto K, Takase K, Yamamoto Y, Doi Y, Taguchi S: Chimeric enzyme composed of polyhydroxyalkanoate (PHA) synthases from Ralstonia eutropha and Aeromonas caviae enhances production of PHAs in recombinant Escherichia coli. Biomacromolecules 2009, 10:682-685.

25. Nomura CT, Taguchi K, Taguchi S, Doi Y: Coexpression of genetically engineered 3-ketoacyl-ACP synthase III $(\mathrm{fabH})$ and polyhydroxyalkanoate synthase ( $p h a C$ ) genes leads to short-chainlength-medium-chain-length polyhydroxyalkanoate copolymer production from glucose in Escherichia coli JM109. Appl Environ Microbiol 2004, 70:999-1007.

26. Nomura CT, Tanaka T, Gan Z, Kuwabara K, Abe H, Takase K, Taguchi K, Doi Y: Effective enhancement of short-chain-length-medium-chain-length polyhydroxyalkanoate copolymer production by coexpression of genetically engineered 3-ketoacyl-acyl-carrier-protein synthase III $(\mathrm{fabH})$ and polyhydroxyalkanoate synthesis genes. Biomacromolecules 2004, 5:1457-1464.

27. Nomura CT, Tanaka T, Equen TE, Appah AS, Matsumoto K, Taguchi S, Ortiz $\mathrm{CL}$, Doi Y: FabG mediates polyhydroxyalkanoate production from both related and nonrelated carbon sources in recombinant Escherichia coli LS5218. Biotechnol Prog 2008, 24:342-351.

28. Carrier TA, Keasling JD: Controlling messenger RNA stability in bacteria: strategies for engineering gene expression. Biotechnol Prog 1997, 13:699-708

29. Carrier TA, Keasling JD: Library of synthetic 5 ' secondary structures to manipulate mRNA stability in Escherichia coli. Biotechnol Prog 1999, 15:58-64.

30. Burgess-Brown NA, Sharma S, Sobott F, Loenarz C, Oppermann U, Gileadi O: Codon optimization can improve expression of human genes in Escherichia coli: a multi-gene study. Protein Expr Purif 2008, 59:94-102.

31. Gao Z, Li Z, Zhang Y, Huang H, Li M, Zhou L, Tang Y, Yao B, Zhang W: High-level expression of the Penicillium notatum glucose oxidase gene in Pichia pastoris using codon optimization. Biotechnol Lett 2012, 34:507-514

32. Menzella HG: Comparison of two codon optimization strategies to enhance recombinant protein production in Escherichia coli. Microb Cell Fact 2011, 10:15.

33. Li QA, Chen QA, Li MJ, Wang FS, Qi QS: Pathway engineering results the altered polyhydroxyalkanoates composition in recombinant Escherichia coli. New Biotech 2011, 28:92-95.

34. Marchisio MA, Rudolf F: Synthetic biosensing systems. Int J Biochem Cell Biol 2011, 43:310-319. 
35. Ellis $T$, Adie $T$, Baldwin GS: DNA assembly for synthetic biology: from parts to pathways and beyond. Integr Biol (Camb) 2011, 3:109-118.

36. Puigbo P, Guzman E, Romeu A, Garcia-Vallve S: OPTIMIZER: a web server for optimizing the codon usage of DNA sequences. Nucleic Acids Res 2007, 35:W126-131.

37. Spratt SK, Ginsburgh CL, Nunn WD: Isolation and genetic characterization of Escherichia coli mutants defective in propionate metabolism. J Bacteriol 1981, 146:1166-1169.

38. Spiekermann P, Rehm BH, Kalscheuer R, Baumeister D, Steinbüchel A: A sensitive, viable-colony staining method using Nile red for direct screening of bacteria that accumulate polyhydroxyalkanoic acids and other lipid storage compounds. Arch Microbiol 1999, 171:73-80.

39. Chen JY, Liu T, Zheng Z, Chen JC, Chen GQ: Polyhydroxyalkanoate synthases PhaC1 and PhaC2 from Pseudomonas stutzeri 1317 had different substrate specificities. FEMS Microbiol Lett 2004, 234:231-237.

40. Qiu YZ, Han J, Guo JJ, Chen GQ: Production of poly(3-hydroxybutyrate-co3-hydroxyhexanoate) from gluconate and glucose by recombinant Aeromonas hydrophila and Pseudomonas putida. Biotechnol Lett 2005, 27:1381-1386.

41. Kato M, Bao HJ, Kang CK, Fukui T, Doi Y: Production of a novel copolyester of 3-hydroxybutyric acid and medium chain length 3-hydroxyalkanaic acids by Pseudomonas sp 61-3 from sugars. Appl Microbiol Biotechnol 1996, 45:363-370.

doi:10.1186/1475-2859-11-130

Cite this article as: Gao et al:: Production of copolyesters of 3-

hydroxybutyrate and medium-chain-length 3-hydroxyalkanoates by $E$. coli containing an optimized PHA synthase gene. Microbial Cell Factories 2012 11:130.

\section{Submit your next manuscript to BioMed Central and take full advantage of:}

- Convenient online submission

- Thorough peer review

- No space constraints or color figure charges

- Immediate publication on acceptance

- Inclusion in PubMed, CAS, Scopus and Google Scholar

- Research which is freely available for redistribution 